\title{
TORNAR-SE ALUNO - IDENTIDADE E PERTENCIMENTO: PERSPECTIVAS ETNOGRÁFICAS ${ }^{1}$
}

\author{
ALVES, Caroline Diniz Nóbrega²
}

Paula Almeida de Castro doutorou-se em Educação no Programa de Educação da Universidade do Estado do Rio de Janeiro (ProPEd/UERJ) e atualmente é professora do Centro de Educação, do Programa de Formação de Professores e coordenadora institucional do Programa de Bolsa de Iniciação à Docência (PIBID/CAPES).

O trabalho desenvolvido pela professora Paula Castro é revelador e sensível quanto ao uso da etnografia na educação com destaque para o uso da fotografia e a participação dos alunos como sujeitos da pesquisa num processo de compreender o aluno como pesquisador. Explora, ainda, as possibilidades da perspectiva colaborativa buscando, com os sujeitos da pesquisa, o olhar etnográfico de insider e outsider sobre a escola e a sala de aula. Os caminhos percorridos para a composição da pesquisa etnográfica destacam os muitos e complexos processos de tornar-se aluno que os sujeitos das escolas públicas percorrem durante os anos de formação. Alguns por sua forma peculiar permanecem, enquanto outros evadem buscando outras formas de sobrevivência - podendo ou não retornar futuramente para os bancos escolares.

A obra conduz, como destaca a professora que prefaciou o livro - Carmen de Mattos (UERJ) - o leitor a desvendar os (des)caminhos da escolarização em uma escola de educação pública situada na Baixada Fluminense do Estado do Rio de Janeiro. Alguns podem pensar tratar-se de uma escola distante (no Sudeste), mas ao iniciar a leitura dos capítulos, tanto professores, quanto alunos nos identificamos com cenas que vivenciamos no nosso cotidiano e, mais ainda, não somente como professores, mas também como alunos. 0 que nos leva a um questionamento: está a escola pública brasileira preparada para a diversidade de sujeitos que vem recebendo e que receberá?

Para esta pergunta, o livro traz a questão referente ao termo resiliência associado ao pertencimento e identidade. A pesquisa, apresentada no livro, retoma a ideia de flexibilidade, mobilidade, fluidez, mutabilidade, para demonstrar a capacidade transformativa dos sujeitos sociais em sua busca incessante para adaptar-se ao mundo, ao universo da escolar.

As análises dos processos de construção do conhecimento e suas interfaces com os estudos sobre a identidade, o pertencimento e a resiliência nos três grupos de participantes em diferentes níveis de ensino: Educação Infantil, Ensino Fundamental e Ensino Superior. Assim, o tornar-se aluno, a que este estudo se reporta, envolve a perspectiva crítica-reflexiva

\footnotetext{
${ }^{1}$ CASTRO, Paula Almeida de. Tornar-se aluno - identidade e pertencimento: perspectivas etnográficas. Campina Grande: EDUEPB, 2015. 272p.

${ }^{2}$ Mestranda do Programa de Pós-Graduação em Formação de Professores da Universidade Estadual da Paraíba. Email: caroldiniz23@hotmail.com
} 
dos alunos pesquisados e da própria aluna-pesquisadora que se interpenetram para alicerçar o sentido da construção do saber que não se limita ao exercício do papel do aluno. Desse modo, ao propor uma forma de repensar o sujeito da educação brasileira, busca-se estabelecer uma interface entre os conceitos de identidade, pertencimento e resiliência para compreender a interlocução entre eles e os processos de tornar-se aluno. Para tal, foram feitos os seguintes questionamentos:

i) Como a identidade é conceituada visando compreender o sujeito contemporâneo?

ii) Como os conceitos de identidade, pertencimento e resiliência contribuem para o entendimento sobre como tornar-se aluno no contexto da escola e da sala de aula?

iii) De que modo o conceito de resiliência oferece explicações para a compreensão dos processos de tornar-se aluno?

A composição deste trabalho busca obter respostas a esses questionamentos, consciente da transitoriedade e da diversidade que compõem a escolarização, sobretudo, no Brasil. Historicamente o aluno, foi considerado como desprovido de conhecimento, designado para frequentar espaços que, de um século a outro, passaram por inúmeras transformações até serem denominados escola. As experiências do sujeito contemporâneo são ampliadas em função, por exemplo, da virtualização dos processos de comunicação, facilitando o acesso às informações e a aquisição do conhecimento em nível global. Essa virtualização redimensiona o papel do aluno. Ele passa a ser pensado como um sujeito autônomo em termos de apreensões teóricas sobre o mundo e na condição de mediador dos conhecimentos e das informações que adquire através de diferentes fontes. Desse modo, o aluno constrói o seu conhecimento no espaço da escola e do tempo, compreende o movimento dinâmico de tornar-se, de permanecer e de se construir como aluno.

A escola é o local no qual o aluno permanecerá por um tempo significativo promovendo a produção do conhecimento. Ao ser tal espaço, que igualmente é chamado a ser pensado no contexto da educação inclusiva, o delineamento de um cenário escolar inclusivo informa quanto à necessidade de que as pesquisas realizadas nesses espaços contribuam para possíveis direcionamentos em função de uma educação de qualidade para todos. Nesse sentido, apontam-se as nuances do processo de entendimento sobre as políticas de inclusão e de como é possível, através da perspectiva dos alunos, compreender a questão sobre como e quem a escola inclui ou exclui.

Para compreender as questões que foram direcionadas para o entendimento das vozes dos alunos nos contextos de desigualdade educacional, cabe destacar a abordagem etnográfica de pesquisa. A proposta de ouvir o aluno encontrou nos estudos etnográficos uma via pela qual suas individualidades são evidenciadas na totalidade da escola, para desse modo criar possibilidades de se repensar as práticas de sala de aula. Esta proposta surge como uma resposta aos questionamentos sobre a validade de dar a palavra, dar a voz aos sujeitos. Nesse sentido, nessa pesquisa "dar a voz" aos sujeitos significa ouvir o que eles têm a dizer sobre as questões propostas para a realização do estudo, ou seja, como o sujeito da pesquisa elabora e reelabora o seu saber sobre o objeto de pesquisa, ressignificando-o. A palavra carrega um dizer único. É necessário ouvir. Para compreender o sujeito é, antes, preciso ouvir e analisar a sua fala a partir dela mesma. As análises partem do que ele expressa através de sua narrativa. A interpretação se dá pelo envolvimento do pesquisador 
com o sujeito da pesquisa de modo a perceber as nuances do processo de fazer sentido de sua fala. No complemento do ouvir, a pesquisadora utilizou a fotografia na tentativa de captar a perspectiva dos sujeitos alunos de modo que, aos nos aproximarmos, fosse possível ampliar a compreensão da vivência escolar e do fazer cotidiano. A fotografia, combinada com as imagens de vídeo, a observação participante e a entrevista, acrescentou aos dados de pesquisa o olhar dos alunos, entendido como neutro no que concernem as teorizações sobre as práticas e os atores escolares.

O resultado das fotografias realizadas pelos alunos constituiu um momento reflexivo, no qual, foi possível significar cada imagem quanto ao que significava para eles tornar-se aluno, ser aluno naquele contexto escolar. O terceiro momento se constituiu em uma devolução para os alunos sobre o que foi produzido e utilizado como parte do estudo realizado. Para a devolução, organizaram-se todas as fotografias, agora reveladas, em um mural no auditório da escola. Nesse dia, os alunos selecionavam as fotografias e as contextualizavam para a equipe. O momento de devolução foi complementado com redações sobre o "significado para eles de ser aluno" e entrevistas individuais onde esclarecíamos outras dúvidas surgidas nas análises preliminares.

As fotos continham em si não apenas momentos agradáveis na escola. Os alunos buscaram situações que os desagradavam ou ainda pessoas e/ou lugares que eles não conheciam para fotografar. Os alunos, exceto dois deles que eram repetentes, não conheciam os demais espaços da escola, exceto a sala de aula. Era o primeiro ano na instituição, onde aproveitaram a possibilidade de fotografar para circularem livremente pela escola e conhecer os locais aos quais não possuem acesso diariamente,como a biblioteca e a sala de informática. As fotos, que pareciam inertes ao olhar do pesquisador movimentavamse nas narrações que os alunos produziam. As fotos refletiam um momento na história do sujeito que o pesquisador não esteve presente se esforçando para aproximar-se o máximo possível da realidade estudada. A foto refletiu o momento/espaço que cada sujeito desejou apreender naquela imagem estática impressa na fotografia.

Para analisar e tematizar os dados da pesquisa foi utilizado o software Atlas.ti. 0 processo de análise de dados de uma pesquisa envolve um longo e cuidadoso trabalho, mesmo que as análises tenham sido realizadas ao longo do período de coleta dos dados construindo e reconstruindo os parâmetros de investigação no campo a partir da continuidade e reflexividade, presentes nas análises. Destaca-se que a realização de análise de dados pelo Atlas.ti está pautada em quatro pontos de referência: (1) visualização dos dados; (2) integração dos dados; (3) encontrar dados que não estavam sendo procurados e (4) explorar teorias originárias de pesquisas de natureza etnográfica e a Groundedtheory. 0 software possibilita a análise nos níveis textual e conceitual (conectando as categorias), permite a gestão de imagens e textos dos dados, classifica em famílias grupos de categorias de acordo com a escolha do pesquisador, exporta a codificação para tabelas em Excel e armazena as análises realizadas. A finalidade do ATLAS.ti consiste em, dentre outras possibilidades, auxiliar investigadores a descobrir e analisar sistematicamente os termos complexos em dados de texto e multimídias. Fornecer as ferramentas para encontrar, codificar e anotar resultados do material de pesquisa em uma fase preliminar às análises dos dados para pesar e avaliar sua importância, para visualizar relações complexas entre elas. Todo o processo de pesquisa e análise de dados é longo e demanda dedicação dos sujeitos envolvidos. Para complementar as tematizações o livro apresenta um Glossário (p.267) com a definição dos termos definidos a partir da análise dos dados da pesquisa e próprios do contexto do estudo. 
As tematizações geradas do processo de análise estão abaixo identificados nos diagramas baseados na dialética do processo de tornar-se aluno. Ao lado de cada tematização, a autora retira algumas falas de sujeitos participantes da pesquisa para apresentar a percepção dos mesmos quanto ao processo de escolarização (CASTRO, 2015, p. 240-241).

\section{Identidade - Pertencimento - ResiliênCIA}

\section{Dever - Saber - Fazer}

Identidade Pertencimento Resiliéncia
Ih minha mãe falava assim: 'Estudar pra quê?' Ela falava assim: 'Homem vira bandido, mulher vira piranha!' Eu era uma menina com catorze anos, e minha mãe falava isso pra mim. Graças a Deus, eu agradeço sempre a Deus, porque isso tudo eu ia excluindo. Porque lá no colégio eu me sentia bem, tinha gente que me entendia sabe, lá em casa não tinha nada isso. Então lá era o lugar que eu queria ir [...] (Dionira, $10 \mathrm{p}$, Pedagogia) (CASTRO, 2015, p.240).

Eu lembro muito da cópia, eu odiava fazer cópia, eu odiava fazer cópia (risos). Tem a cópia do castigo e tem a cópia da tarefa (Alexandre, Janaína e Laura $1^{\circ}$ p., Pedagogia) (CASTRO, 2015, p.241).

A gente pinta, tem que ficar escrevendo, às vezes a gente dá uma paradinha, a mão fica doendo, a gente tem que copiar correndo porque a tia apaga o quadro. E ela não deixa ir ao banheiro (Juscelino, $2^{\circ}$ ano E.F.) (CASTRO, 2015, p.240).

Quando penso na minha trajetória escolar, eu não me lembro do que aprendi em questão de matéria e aulas, mas de experiências resultantes da interação com as pessoas, e acima de tudo, amizade (Eduarda, $1^{\text {a }}$ período de Pedagogia) (CASTRO, 2015, p.241).

Na quinta série foi quando eu comecei a andar em grupo entendeu. Porque se você anda com alguém que é bom aluno, no caso meu, quando eu andava com essas meninas na quinta série elas não eram boas alunas, eram como eu era, então não subia, não continuava, continuava naquele patamar ali (Tracy, 10 período de Pedagogia) (CASTRO, 2015, p.241). 
Ao longo do texto o leitor encontra muitas falas que dão conta de explicar as passagens do contexto escolar vivenciado por eles e muitos de nós. Como destaca a autora, sem os sujeitos, não haveria dados, nem estudo ou o que estudar. Os alunos que voluntariamente participaram desse estudo contribuíram para elucidar os processos que os conduziram pelos caminhos da escola. Ao longo do contato com os alunos, foi possível aprender a opinião deles sobre o trabalho que estava sendo realizado sobre seus processos de tornarem-se alunos.

Ainda que muitos dos alunos participantes desse estudo desconheçam o significado de um estudo de pós-graduação, enquanto outros ainda não tenham decidido a resposta para "o que você vai ser quando crescer?", todos se dispuseram a contribuir para os resultados desse estudo. De outra forma, possibilitamos que as memórias dos "tempos de escola" fossem resgatadas para compor essa pesquisa.

Foram muitas formas de contribuir. Pela dúvida, como Gilda que aos 53 anos retornou à universidade para cursar Pedagogia: "É assim, no primeiro momento eu achei, eu até conversei com ela, perguntei se seria útil realmente o meu percurso". Ou ainda como Cátia que se dispôs a participar mesmo sem saber o que dizer: "Aí a redação eu fiz mesmo que eu não lembre de muita coisa, é sempre bom". Além disso, Paula Castro destaca a possibilidade de perceber que, em diferentes momentos, os alunos que fizeram parte da pesquisa foram convidados a contribuir com o processo de análise de dados, compartilhando suas vivências atuais e antigas da escola. Fomos apresentados às trajetórias de cada um em "tornar-se aluno" para que pudessem escrever mais uma página nos estudos em Educação, no sentido de compreender a necessidade de repensar a escola como um espaço partilhado mutuamente entre professores e alunos. 